\title{
HARMONIC SCALPEL OVER ELECTROCAUTERY, EVALUATION OF PEROPERATIVE BLOOD LOSS IN SELECTIVE NECK DISSECTION. A COMPARATIVE STUDY
}

\author{
Agrawal $M^{1^{*}}$, Thakur $S K^{2}$, Rahman $Q B^{3}$, Agrawal $A^{4}$, Agrawal $N B^{5}$
}

\section{Affiliation}

1. Lecturer, Department of Oral and Maxillofacial Surgery, Birat Medical College and Teaching Hospital, Biratnagar, Nepal

2. Lecturer, Department of Otorhinolaryngology, Head \& Neck Surgery, Nobel Medical College and Teaching Hospital, Biratnagar, Nepal

3. Professor and Chairman, Department of Oral and Maxillofacial Surgery, Bangabandhu Sheikh Mujib Medical University (BSMMU), Dhaka.

4. Dental Surgeon, Biratnagar Hospital Pvt. Ltd., Biratnagar, Morang, Nepal

5. Dental Surgeon, Golden Hospital Pvt. Ltd., Biratnagar, Morang, Nepal

\section{ARTICLE INFO}

Article History

Received : 06 July, 2018

Accepted : 21 August, 2018

Published : 31 August, 2018

(C) Authors retain copyright and grant the journal right of first publication with the work simultaneously licensed under Creative Commons Attribution License CC - BY 4.0 that allows others to share the work with an acknowledgment of the work's authorship and initial publication in this journal.

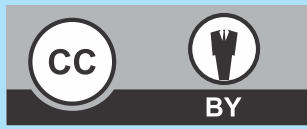

ORA 78

DOI: http://dx.doi.org/10.3126/bjhs.v3i2.20964

* Corresponding Author

Dr Manish Agrawal

Lecturer

Department of Oral and Maxillofacial Surgery

Birat Medical College and Teaching Hospital, Biratnagar, Nepal

Email: dr.agrawal.manish@gmail.com

ORCID: https://orcid.org/0000-0002-8958-4107

\section{Citation}

Agrawal M, Thakur SK, Rahman QB, Agrawal A, Agrawal NB. Harmonic Scalpel Over Electrocautery, Evaluation of Peroperative Blood Loss in Selective Neck Dissection. A Comparative Study. BJHS 2018;3(2)6:475-479

\section{ABSTRACT}

\section{Introduction}

The use of Harmonic Scalpel (HS) over Electrocautery (EC) in neck dissection has become standard of care in recent years. However, both the devices are presently widely used in practice and still serve large number of patients globally according to surgeon's choice and cost effectiveness.

\section{Objective}

To evaluate the amount of peroperative blood loss in cancer patient undergoing selective neck dissection (Levels I, II and III) with Harmonic Scalpel (HS) and Electrocautery (EC).

\section{Methodology}

The study was performed in the Department of Oral and Maxillofacial Surgery, Faculty of Dentistry, Biratnagar Hospital PVT LTD and Birat Medical College and Teaching Hospital, Nepal from June 2012 to February 2018. A total of 40 patients, 27 male and 13 female, aged 45 to 70 years diagnosed with oral cavity cancer were included in this prospective study. Two groups were formed, 20 patients in each group based on the surgical instrument used; Harmonic Scalpel (HS) and Electrocautery (EC). Data for age and sex of the patients were collected preoperatively. The surgery was performed under general anesthesia with endotracheal intubation and standard protocol was maintained during surgery. Amount of peroperative blood loss was measured and recorded. Data was processed and analyzed using SPSS and was compiled and test of significance was done using unpaired't' test.

\section{Results}

The amount of peroperative blood loss was significantly lower in Harmonic Scalpel (HS) group then in Electrocautery (EC) group.

\section{Conclusion}

Results from this study suggests that the Harmonic Scalpel (HS) is an effective device to reduce peroperative blood loss during selective neck dissection.

\section{KEYWORDS}

Harmonic scalpel, electrocautery, oral carcinoma, selective neck dissection (SND). 


\section{INTRODUCTION}

In Head and Neck region, squamous cell carcinoma (SCC) is the most common form of malignancy. Management of primary lesion, regional nodes and distant metastasis is the three major components of the treatment of the oral cancer. Wide three dimensional (3D) surgical excision of primary lesion followed by neck dissection is still main protocol of treatment for all operable cases. Harmonic Scalpel (HS) added a new dimension in addition to Electrocautery (EC) with minimal blood loss specially in case of tongue and neck. Cancer is the end product of an unregulated proliferation of cells resulting from mutations in precursor cell. ${ }^{1}$ Oral cancer is the $8^{\text {th }}$ most frequent cancer in the world among males and $14^{\text {th }}$ among females. ${ }^{2}$ The incidence of oral cancer in male is $8.0 \%$ and female is $4.3 \%$ in India and $12.3 \%$ and $8.7 \%$ respectively for male and female in Pakistan.

Oral cancer has a predilection for spread to levels I to III, the risk of involvement of level IV increases from $3 \%$ to $17 \%$ for the oral cancer that have spread to level I, II or III whereas the risk for involvement of level $\mathrm{V}$ is from $1 \%$ to $6 \%$. Oral cancer with clinically $\mathrm{N}_{\mathrm{o}}$ necks, it is safe to dissect level I, II and III only and if there is any clinically evident nodal disease in levels I, II or III then it will be safe to dissect upto level IV. ${ }^{4}$ Neck dissection is a well established procedure for loco regional control of the lymphatic spread for oral cancer. ${ }^{5}$ The technique of neck dissection has been evolved from the radical neck dissection to the selective neck dissection. The standard approach for clinically negative neck is the selective removal of only those nodes at greatest risk for metastatic disease and this procedure has been well accepted as a staging procedure and selective neck dissection provides valuable pathological information for staging and for addition of further adjuvant treatment. ${ }^{6}$

Two major factors to avoid unwanted damage to the adjacent structures and to ensure a dry operating field are proper haemostasis and meticulous neck dissection. Most of the studies have evaluated the correlation of duration of surgery and loss of blood in major head and neck surgery. Prolong the anesthetic time $\geq 8$ hours greater will be the risk of postoperative complications. ' Perioperative blood transfusion and peroperative blood loss was associated with increased length of hospital stay. ${ }^{8}$ Advanced surgical technology has proposed one of the promising surgical device, HS, to treat metastatic head and neck cancer that improves several negative consequences of the surgery and leads to early patient recovery, reduction in duration of surgery and minimal peroperative blood loss.

HS is an ultrasonically activated surgical instrument where high frequency mechanical energy or vibration at $55.5 \mathrm{kHz}$ is used to cut and coagulate the vessels or tissues simultaneously at low temperature $\left(80^{\circ} \mathrm{C}\right)$ without any electrical current. ${ }^{9} \mathrm{EC}$ is a surgical device that produces smoke and is used to cut and coagulate the vessels or tissues at high temperature $\left(200^{\circ} \mathrm{C}\right)$ that leads to carbonization of the adjoining tissues. ${ }^{10}$ Ultarsonic coagulation achieved by HS is similar to that of EC but the mechanism by which the tissue proteins become denatured is completely different. To denature protein HS break tertiary hydrocarbon bonds by transferring adequate mechanical energy using ultrasonic vibration whereas EC form coagulum by heating tissues to denature protein. ${ }^{11}$ Tissue dissection and clogging of minor blood vessel occurs at same time with HS hence reduction in thermal damage of adjacent structures. The lateral tissue injury, for HS ranges from 0 to $1000 \mu \mathrm{m}$ whereas for EC ranges from $240 \mu \mathrm{m}$ to $15 \mathrm{~mm} .{ }^{12}$ More efficient and safe surgery was achieved with HS due to reduction in operative time by $50 \%$, bloodless operative field, adequate view, proper and easier identification of anatomical structures and minimum requirement for coagulation of small blood vessels hence. The duration of operation, the dosage of anesthetic drugs and the cost was reduced when HS was used in compare to EC. Peroperative blood loss was reduced by five times, the duration of surgery decreased and adequate and more precise haemostasis was achieved with HS when compared to EC. Thus, the need for blood transfusion was reduced when HS was used. ${ }^{5}$ Therefore the present study is designed to evaluate the amount of peroperative blood loss in cancer patient undergoing selective neck dissection (Levels I, II and III) with Harmonic Scalpel (HS) and Electrocautery (EC) in our setting.

\section{METHODOLOGY}

The prospective interventional study was performed in the Department of Oral and Maxillofacial Surgery, Faculty of Dentistry, Birat Medical College and Teaching Hospital, Biratnagar, from June 2012 to February 2018. All the patients signed written, informed consent. A total of 40 patients, 27 male and 13 female, aged 45 to 70 years diagnosed with cancer of oral cavity requiring selective neck dissection (Levels I, II and III) were included in this study. Diagnosis was made by accurate history, clinical examinations, imaging and histopathological examination. Preoperative characteristics for all enrolled patients including age, sex, primary tumor location and staging of cancer (TNM) were collected at the time of their enrollment. Inclusion criteria: Oral cavity cancer $\left(\mathrm{T}_{1}-\mathrm{T}_{4}\right)$, clinically negative neck node $\left(\mathrm{N}_{0}\right)$, age: $45-70$ years, selective neck dissection (Levels I-III), no evidence of distant metastasis on clinical and radiological examination, no prior head and neck surgery and chemo-radiation.

The patients were categorized into 2 groups, 20 patients in each group based on surgical device used, HS and EC. Group I comprised 20 patients undergoing selective neck dissection with HS. Group II comprised 20 patients undergoing selective neck dissection with conventional EC. The surgery was performed by same operating team of experienced Oral and Maxillofacial Surgeons under general anaesthesia with endotracheal intubation. Standard protocol was used giving submandibular incision and raising subplatysmal skin flap. A closed suction drain was placed in all the patients at the end of the surgery for 24-48 hrs postoperatively. The wound was closed in layers with absorbable sutures and skin with stapples. Amount of peroperative blood loss was measured and recorded. Blood loss was measured as follows; 1) Gauzes were weighed 
before and after surgery. 2) Volume of drainage in the suction container minus any irrigation used during dissection (1 $\mathrm{g}=1 \mathrm{ml}$ of blood).

The data were analyzed with the help of software program SPSS. The evaluation was done by unpaired't' test. The results were considered significant if $p$ value was $\leq 0.05$. Tables and bar diagram were used to show the results.

\section{RESULTS}

Out of 40 patients (Group I $=20$ patients and Group $=20$ patients). The youngest patient was 45 years old and the oldest patient was 70 years old, 27 (67.5\%) patients were male and $13(32.5 \%)$ patients were female. The mean age of the patients was $56.45 \pm 7.17$ years with most common range of $56-60$ years in Group I and $56.55 \pm 7.22$ years with most common range of 51-55 years in Group II (Table-1). The majority of patients were $\geq 50$ years. Peroperative blood loss was measured in relation to 2 groups. Blood loss was measured as follows; 1) Gauzes were weighed before and after use. 2) Volume of drainage in the suction container minus any irrigation used during dissection (Table-2) $(1 \mathrm{gm}=1 \mathrm{ml}$ of blood). Peroperative blood loss (Table-2) of Group I vs Group II was $19.60 \mathrm{ml}$ vs $74 \mathrm{ml}$ respectively, $\mathrm{p}<0.001$ which was statistically significant thus the blood loss with HS was less when compared to EC in selective neck dissection.

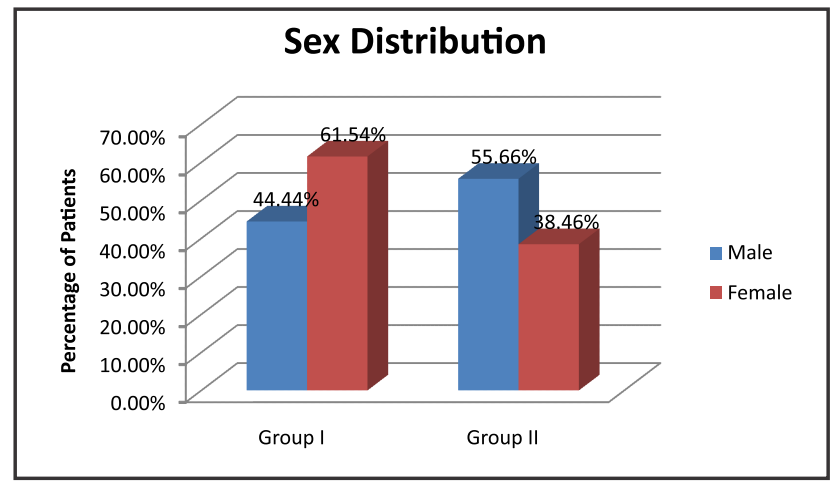

Figure 1: Showing sex distribution between Group I and Group II.

Table -1: Distribution of groups by age. $(\mathrm{N}=40)$

$$
\text { Variable }
$$

Group I

Group II

\section{Age}

Mean \pm SD

$56.45+7.17 \quad 56.55 \pm 7.22$

Table 2: Comparision of peroperative blood loss between Group I and Group II

$\begin{array}{cc}\begin{array}{c}\text { Peroperative Blood Loss } \\ \text { in } \mathrm{ml}\end{array} & \begin{array}{c}\mathrm{P} \text { value } \\ \mathrm{P}<0.05\end{array} \\ \text { Mean } \pm \text { SD in } \mathrm{ml} & \\ 19.60 \pm 4.135 & 0.001^{\mathrm{s}} \\ 74 \pm 12.645 & \end{array}$

$\mathrm{s}=$ significant, Statistical analysis was done by unpaired ' $\mathrm{t}$ ' test.

\section{DISCUSSION}

Blood transfusion and prolonged duration of surgery are always associated with unwanted effects in those patients undergoing major head and neck surgery. It is worth investigating the procedure to reduce the bleeding, hence, this study shows that the surgery performed by HS significantly reduces blood loss in patients undergoing selective neck dissection for oral cavity cancer. Our study was performed to evaluate if HS is superior to EC. Bleeding causes confusion of the anatomic and surgical planes, increases operative time and necessitates the placement of drains. HS has an advantage over EC, it increases visibility, decrease blood loss peroperatively, reduces operative time and helps avoid placement of drain in neck dissection. ${ }^{13,14}$ Perioperative blood transfusion is more or less associated with reduced long term survival of the patient and high recurrence rate in various types of cancer; head and neck, sarcoma, lung, breast, gastric, hepatocellular, renal cell carcinoma, prostate and colorectal. ${ }^{15-22}$ United States Food and Drug Administration has approved the use of HS for the ligation of vessels up to $3 \mathrm{~mm}$ in diameter. Thermal damage is limited to $0-2 \mathrm{~mm}$ beyond the tissue grasped within the forceps of the device. ${ }^{23,24}$ Harmonic ACE is a second generation HS which is even more appropriate for clogging vessels up to $5 \mathrm{~mm}$ in diameter. ${ }^{13}$ The advancement in technologies used in surgical practice have made the surgery simple with the use of a wide variety of energy sources for tissue dissection likewise HS is a new surgical device that cuts and coagulates by converting electrical energy into ultrasonic mechanical vibrations and the device is composed of a power generator, an ultrasonic acoustic system and a surgical blade. ${ }^{25}$ Urquhart et al demonstrated in a period of three years that total peroperative blood loss is an indicator for the amount and duration of postoperative drainage in neck dissection. ${ }^{26} \mathrm{HS}$ was initially developed for laparoscopic surgery alone later on some authors reported its effectiveness in head and neck surgery, neck dissections, parotid, submandibular and thyroid gland surgery also. Few authors reported that the peroperative blood loss was around $58 \mathrm{ml}$ vs $24 \mathrm{ml}$ in HS vs EC respectively. ${ }^{29}$ In a prospective study, the patients in the HS group has significantly less peroperative bleeding, $5.0 \mathrm{ml}$ vs $16.5 \mathrm{ml} \mathrm{HS}$ vs EC respectively; $\mathrm{p}<0.001 .^{30}$ Blood loss and operative time was significantly reduced in HS vs EC group, $127 \mathrm{ml}$ vs $210 \mathrm{ml}$ respectively, hence, $p>0.05 .^{31}$ The study conducted by us showed that the peroperative blood loss (Table-2) in Group I vs Group II was $19.60 \mathrm{ml}$ vs $74 \mathrm{ml}$ respectively, $p<0.001$ which was statistically significant hence the blood loss with HS was reduced in compared to EC in selective neck dissection. There was a $60.8 \%$ reduction in peroperative bleeding when HS was used. ${ }^{13}$ Hallgrimsson et al reported that peroperative blood loss in HS and EC group was $69 \mathrm{ml}$ and $79 \mathrm{ml}$ respectively, $p=0.42$, hence there was minimum difference in peroperative bleeding between two groups. ${ }^{32}$ Walen et al showed blood loss of $62 \mathrm{ml}$ vs $158 \mathrm{ml}$ in HS vs EC group respectively, $p=0.02$, hence the difference was statistically significant. $^{33}$ Ali et al reported mean age of patients was $28.07 \pm 7.35$ years, range (18-42) years and $29.43 \pm 1.22$ years, 
range (18-68) years, $\mathrm{p}=0.573$ whereas mean peroperative blood loss was $2.40 \pm 2.74 \mathrm{ml}$ and $3.43 \pm 3.42 \mathrm{ml}$, in HS and EC group respectively, no significant difference was observed whereas our study showed that the mean age of the patients was $56.45 \pm 7.17$ years, range (56-60) years in Group I and $56.55 \pm 7.22$ years, range (51-55) years in Group II. ${ }^{34}$ The simultaneous coagulation and cutting of vessels and tissue without the need to change the instruments is most likely the primary reason for significant decrease in operative time and peroperative blood loss. HS generates relatively low temperature and transfer low level of thermal energy to the surrounding tissues, that avoids the necrosis of the surgical margins and therefore potentially reduce the risk of postoperative complications.

\section{CONCLUSION}

Harmonic Scalpel (HS) is an effective device to reduce peroperative blood loss during selective neck dissection. Decreased blood loss, enhanced visibility and better postoperative outcomes are the strong reasons to consider HS as a step forward over conventional Electrocautery in selective neck dissection.

\section{RECOMMENDATION}

Further studies with more advanced technology and modern instruments can be done to obtain more accurate results and greater logistic support are required to determine whether the HS has an advantage over EC in reducing peroperative blood loss during selective neck dissection. Management of oral carcinoma should always be coordinated by a multidisciplinary team including Oral \& Maxillofacial Surgeons, Oncologists, Radiotherapists, Speech Therapists and ENT Surgeons.

\section{LIMITATION OF THE STUDY}

Presence of irrigating fluids, evaporation and loss of blood on the floor of operating room complicates to carefully and exactly measure the total amount of blood loss per and postoperatively. Thus, comparison of peroperative blood loss from one institution to another or from one surgeon to another can vary accordingly.

\section{ACKNOWLEDGEMENT}

We would like to acknowledge each and every member of Department of Oral and Maxillofacial Surgery, Birat Medical college \& Teaching Hospital, Biratnagar, Morang, Nepal and my colleagues from other Department (ENT), for their continuous and immense support. Their patience, motivation and logical way of thinking helped me during writing of this research article.

\section{CONFLICT OF INTEREST}

None

\section{CONFLICT OF INTEREST}

None

\section{FINANCIAL DISCLOSURE}

None

\section{REFERENCES}

1) Marx RE, Stern $D$ (ed.). Premalignant and malignant epithelial tumors of mucosa and skin'. In: Oral and maxillofacial pathology: a rationale for diagnosis and treatment. Quintessence Publishing $\mathrm{Co}$, Inc, Illinois, 2003; pp. 283-91.

2) Fritz $A$, Percy $C$, Jack $A$ (ed.). International classification of diseases for oncology. 3rd ed, Geneva: World Health Organization, 2000.

3) Cancela MC, Voti L, Guerra M, Chapui F, Mazuir M, Curado MP. Oral cavity cancer in developed and in developing countries: populationbased incidence. Head Neck, 2010;10:357-367. doi: 10.1002/hed.21193.

4) Shah JP, Candela FC, Poddar AK. The pattern of cervical lymph node metastases from squamous carcinoma of the oral cavity. Cancer, 1990;66: 09-13. https://doi.org/10.1002/1097-0142(19900701) $66: 1<109$

5) Marcin KOS, Engelke W. Advantages of a new technique of neck dissection using an ultrasonic scalpel. J Cranio Maxillofac Surg, 2007; 35: 10-14. DOI: 10.1016/j.jcms.2006.10.007

6) Hao SP, Tsang NM. The role of supraomohyoid neck dissection in patients of oral cavity carcinoma. Oral Oncology, 2002;38: 309-312. PMID: 11978555

7) Farwell DG, Reilly DF, Weymuller EA Jr, Greenberg DL, Staiger TO, Futran NA. Predictors of perioperative complications in head and neck patients. Arch Otolaryngol Head Neck Surg, 2002;128:505-511. PMID:12003580
8) Girod A, Brancati A, Mosseri V, Kriegel I, Jouffroy T, Rodriguez J. Study of the length of hospital stay for free flap reconstruction of oral ans pharyngeal cancer in the context of the new French casemix-based funding. Oral Oncol, 2010;46: 190-194.

9) Mantke R, Pross $M$, Klose $S$, Lehnert $H$, Lippert $H$. Einsatz des Schildrfisenchirurgie. Chirurg, 2003; 74: 739-742.

10) Metternich FU, Wenzel S, Sagowski $C$ et al. Surgical treatment of rhinophyma with the ultrasonic scalpel (Ultarcision harmonic scalpel). Laryngorhinootologie, 2003; 82:132-7.

11) Walker RA, Syed ZA. Harmonic scalpel tonsillectomy versus electrocautery tonsillectomy: a comparative pilot study. Otolaryngol Head Neck Surg, 2001; 125: 449-55.

12) McCarus SD. Physiology mechanism of the ultrasonically activated scalpel. J Am Assoc Gynecol Laprosc, 1996;3: 601-8.

13) Barczynski M, Konturek A, Cichon S. Minimally invasive videoassisted thyreoidectomy (MIVAT) with and without use of Harmonic Scalpel-a randomized study. Langenbacks Arch Surg, 2008;393: 647-54.

14) Koh YW, Park JH, Lee SW, Choi EC. The Harmonic Scalpel technique without supplementary ligation in total thyroidectomy with central neck dissection: a prospective randomized study. Ann Surg, 2008; 247: 945-9.

15) Yamamoto J, Kosuge T, Takayama $T$ et al. Perioperative blood transfusion promotes recurrence of hepatocellular carcinoma after hepatectomy. Surgery 1994; 11:303-9.

16) McClinton S, Moffat LEF, Scott S, Urbaniak SJ, Kemdge DF. Blood transfusion and survival following surgery for prostatic carcinoma. BrJ Surg 1990; 77:140-2. 
17) Younes RN, Rogatko A, Brennan ME. The influence of intraoperative hypotension and perioperative blood transfusion on disease-free survival in patients with complete resection of colorectal liver metastases. Ann Surg 1991; 214:107-13.

18) Mikulin T, Powell CS, Urwin GH, Hamdy F, Fox M, Williams HL. Relation between blood transfusion and survival in renal adenocarcinoma. BrJ Surg 1986; 73:1036-7.

19) Rosenberg SA, Seipp CA, White DE, Wesley R. Perioperative blood transfusions are associated with increased rates of recurrence and decreased survival in patients with high-grade soft-tissue sarcomas of the extremities. J Clin Oncology 1985; 3:698-709.

20) Chung $M$, Steinmetz OK, Gordon PH. Perioperative blood transfusion and outcome after resection for colorectal carcinoma. Br J Surg 1993; 80:427-32.

21) Fong $Y$, Karpeh $M$, Mayer $K$, Brennan MF. Association of perioperative transfusions with poor outcome in resection of gastric adenocarcinoma. Am J Surg 1994; 167:256-60.

22) Moores DWO, Piantadosi S, McKneally ME. Effect of perioperative blood transfusion on outcome in patients with surgically resected lung cancer. Ann Thorac Surg 1989; 47:346-51.

23) Werther K, Christensen IJ, Nielsen HJ. The association between preoperative concentration of soluble vascular endothelial growth factor, perioperative blood transfusion, and survival in patients with primary colorectal cancer. Eur J Surg, 2001; 167: 287-292

24) McHenry CR, Speroff $T$, Wentworth $D$, Murphy $T$. Risk factors for postthyroidectomy hypocalcemia. Surgery, 1994;116: 641-7.

25) Bliss RD, Gauger PG, Delbridge LW. Surgeon's approach to the thyroid gland: surgical anatomy and the importance of technique. World J Surg, 2000;24:891-7.

26) Awwad JT, Isaacson K. The Harmonic Scalpel: An intraoperative complication. Obstet Gynaecol, 1996; 88: 718-720.
27) Urquhart AC, Berg RL. Neck dissections: predcting postoperative drainage. Laryngoscope, 2002; 112: 1294-1298.

28) Salami A, Bavazzano M, Mora R, Dellepiane M. Harmonic Scalpel in pharyngolaryngectomy with radical neck dissection. J Otolaryngol Head Neck Surg, 2008;37: 633-7.

29) Gilbey P, Gadban H, Letichevsky V, Talmon Y. Harmonic Scalpel tonsillectomy using the curved shears instrument versus cold dissection tonsillectomy: a retrospective study. Ann Otol Rhinol Laryngol, 2008;117:46-50.

30) Schrey A, Pulkkinen J, Fremling C, Kinnunen I. Ultrasonically activated Scalpel compared with Electrocautery in tonsillectomy. ORL J Otorhinolaryngol Relat Spec, 2004;66:136-40.

31) Roth JA, Pincock T, Sacks R, Forer M, Boustred N, Johnston W, et al. Harmonic Scalpel tonsillectomy versus monopolar diathermy tonsillectomy: a prospective study. Ear Nose Throat J, 2008; 87:346-7.

32) Pellegrino A, Fruscio R, Maneo A, Corso S, Battistello M, Chiappa V, Stomati M. Harmonic Scalpel versus Conventional Electrocautery in the treatment of vulvular cancer. Int J Gynaecol Obstet,103:185-8.

33) Hallgrimsson $P$, Loven $L$, Westerdahl $j$, Bergenfelz A. Use of the Harmonic Scalpel versus Conventional haemostatic techniques in patients with Grave disease undergoing total thyroidectomy: a prospective randomized controlled trial. Langenbecks Arch Surg, 2008; 393: 675-680.

34) Walen SG, Rudmik LR, Dixon E, Matthews TW, Nakoneshny SC, Dort JC. The utility of the Harmonic Scalpel in selective neck dissection: A prospective, randomized trial. Otolaryngol Head Neck Surg, 2011; 144: 894-9.

35) Ali NS, Ikram M, Akhter S, Moghira I, Nawaz A, Arain A. Harmonic Scalpel versus Electrocautery tonsillectomy: a comparative study in adult patients. J Pak Med Assoc, 2011; 61:256-9. 